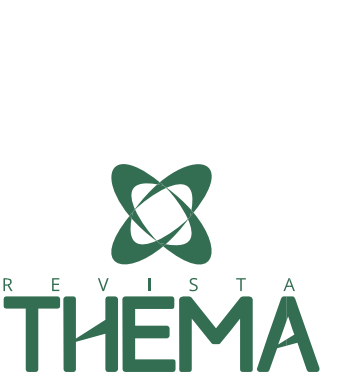

\title{
Componentes curriculares mediados na educação a distância do programa Profuncionário
}

\section{Curricular components mediated in distance learning in the Profuncionário program}

Fernando Treptow Brod ${ }^{1}$; Sheyla Costa Rodrigues²; Luciana Milcarek ${ }^{3}$

\begin{abstract}
RESUMO
O artigo problematiza o processo de mediação pedagógica realizado pelo tutor a distância do Programa PROFUNCIONÁRIO na Rede e-Tec Brasil do Instituto Federal de Educação, Ciência e Tecnologia Sul-riograndense (IFSul). Nesse modelo de ensino, o tutor a distância é contratado para atuar, pelo período de dois anos, em todos os componentes curriculares de um curso técnico. Se, por um lado, isso permite-lhe conhecer a realidade de seus alunos; por outro, exige-lhe um esforço pedagógico de apropriação e mediação dos conteúdos específicos nos diversos componentes curriculares que integram os currículos de cada curso. Como procedimento metodológico, analisou-se as recorrências encontradas nos discursos dos tutores a distância por meio da técnica do Discurso do Sujeito Coletivo (DSC), de Lefèvre e Lefèvre. O estudo aponta que uma rede de conversação recursiva entre o professor formador, o tutor a distância e o tutor presencial possibilita a apropriação de conhecimentos técnicos e específicos necessários ao processo de mediação pedagógica com os estudantes. Essa convivência, no caminho da constituição de um coletivo inteligente, contribui para profissionalizar o processo de mediação pedagógica na educação a distância do programa PROFUNCIONÁRIO.
\end{abstract}

Palavras-chave: Mediação Pedagógica; Educação a Distância; PROFUNCIONÁRIO.

\begin{abstract}
The article questions the process of pedagogical mediation carried out by the distance tutor of the PROFUNCIONÁRIO Program in the e-Tec Brasil Network from the Sul-rio-grandense Federal Institute of Education, Science and Technology (IFSul). In this teaching model, the distance tutor is hired to work, for a period of two years, in all curricular components of a technical course. If, on one hand, this allows him/her to know the students' reality; on the other, it demands from him/her a pedagogical effort of appropriation and mediation of specific contents in several curricular components which integrate the syllabus of each course. As a methodological procedure, we analyzed the recurrences found in the speech of distance tutors through the Collective Subject Discourse (DSC), from Lefèvre and Lefèvre. The study points out that a recursive conversation network between the teacher, the distance tutor and the on-site tutor enables the appropriation of technical and specific knowledge necessary in the process of pedagogical mediation with the students. This interaction, aimed to build an efficient collective, contributes to professionalize the process of pedagogical mediation in distance learning in the PROFUNCIONÁRIO program.
\end{abstract}

Keywords: Pedagogical Mediation; Distance Learning; PROFUNCIONÁRIO.

\footnotetext{
${ }^{1}$ IFSul - Instituto Federal de Educação, Ciência e Tecnologia Sul-rio-grandense, Pelotas/RS - Brasil.

${ }^{2}$ FURG - Universidade Federal do Rio Grande - Rio Grande/RS - Brasil.

${ }^{3}$ IFPR - Instituto Federal de Educação, Ciência e Tecnologia do Paraná - Curitiba/PR - Brasil
} 


\section{INTRODUÇÃO}

A educação profissional a distância mediada por meio das Tecnologias Digitais da Informação e da Comunicação (TDIC) apresenta-se num cenário histórico de expansão da educação profissionalizante, caracterizando-se pela flexibilidade ciberespacial e possibilidades interativas nunca antes imaginadas para uma formação de nível técnico. Contudo, a mediação pedagógica nessa modalidade de ensino ainda se encontra num processo de construção e configuração, pois os professores formadores e os tutores são, originalmente, docentes da educação presencial e, portanto, precisam de um tempo para que possam refletir/aprender sobre os saberes necessários para atuar na EaD.

As possibilidades de interação promovidas pelas ferramentas digitais de comunicação no ciberespaço requerem outra maneira de ensinar e de aprender na educação profissional a distância, motivo pelo qual assume-se o desafio de problematizar o processo de mediação pedagógica realizado pelo tutor a distância nessa modalidade de ensino.

O estudo analisou o processo de mediação pedagógica desenvolvida pelos tutores a distância do Curso Técnico de Multimeios Didáticos no Programa PROFUNCIONÁRIO da Rede e-Tec Brasil realizada no Instituto Federal de Educação, Ciência e Tecnologia Sul-rio-grandense - IFSul - Pelotas/RS no período de junho de 2015 a junho de 2016.

O Programa de Formação Inicial em Serviço dos Profissionais da Educação Básica dos Sistemas de Ensino Público - PROFUNCIONÁRIO, é uma ação do Governo Federal que abrange todo o país. 0 PROFUNCIONÁRIO tem por objetivo promover, por meio da educação a distância, a formação profissional técnica em nível médio de funcionários que atuam nos sistemas de ensino da educação básica pública municipal e estadual, com ensino médio concluído ou concomitante a esse, de acordo com a Portaria do MEC no 1.547, de 24 de outubro de 2011 (PROFUNCIONÁRIO, PPC - IFSul, 2012).

A educação profissional a distância, demarcada neste estudo como campo de análise pelo programa PROFUNCIONÁRIO, tem contratado desde 2012, por meio de edital público, tutores a distância das mais diversas áreas do conhecimento para atuar como mediadores pedagógicos nos Cursos Técnicos de Alimentação Escolar, Infraestrutura Escolar, Secretaria Escolar e Multimeios Didáticos. Observouse o processo de mediação pedagógica realizado pelo tutor a distância, considerando a necessidade de estudos que investiguem as dinâmicas de trabalho do tutor presencial, suas lacunas, limitações, dificuldades e competências específicas com o processo de tutoria na EaD, visto que, a eles cabe estabelecer e promover contato permanente com os alunos nos polos de apoio presencial, buscando acompanhá-los em suas aprendizagens.

É missão dos tutores a distância do PROFUNCIONÁRIO acompanhar os alunos no processo de construção do conhecimento por meio de um Ambiente Virtual de Aprendizagem (AVA), uma tecnologia digital comunicativa com propósito educacional de organização pedagógica e de gestão acadêmica virtual de cursos e disciplinas. Além de dominar o uso dessa tecnologia, necessitam saber usá-la pedagogicamente para mediar os conhecimentos específicos dos componentes curriculares em suas interações com os alunos, o que implica ter o domínio dos conteúdos e o conhecimento pedagógico dos mesmos. Além disso, como são nomeados tutores a distância do curso, necessitam dar conta do processo de mediação pedagógica em aproximadamente 20 componentes curriculares de formação geral e específica de nível médio, ao longo dos dois anos de duração do curso. 
Ao refletir-se sobre tal circunstância e com embasamento nos estudos de Shulman (2010) e Tardif (2012) o estudo buscou conhecer como os tutores a distância do Curso Técnico em Multimeios Didáticos apropriam-se dos conhecimentos específicos nos componentes curriculares de formação geral e específica para mediá-los pedagogicamente com os alunos.

\section{FUNDAMENTAÇÃO TEÓRICA}

A educação a distância (EaD) vem se modificando para uma adequada articulação às tecnologias. As novas formas de comunicação e interação, por meio da Internet impulsionaram e ampliaram sua oferta nos mais diversos níveis de ensino. Para Lévy (1999, p. 167), por meio desse suporte de informação e de comunicação, emergem outros gêneros de conhecimento, "com critérios de avaliação inéditos para orientar o saber", despertando novos atores na produção e tratamento desses conhecimentos.

A demanda por formação não só está passando por um enorme crescimento quantitativo, como também está sofrendo uma profunda mutação qualitativa, no sentido de uma crescente necessidade de diversificação e personalização. Os indivíduos suportam cada vez menos acompanhar "cursos uniformes ou rígidos que não correspondem a suas necessidades reais e à especificidade de seu trajeto de vida". (LÉVY, 1999, p. 169).

A Educação a distância em rede, segundo Moran (2007), avança no sentido de superar a sensação de individualismo e impessoalidade, de que o aluno em um curso nessa modalidade de ensino tem de se isolar em leituras e atividades distantes do mundo e dos outros. Para o autor, a internet traz flexibilidade de acesso aos materiais de estudo, junto com a possibilidade de interação e participação.

Lévy (1998) desterritorializa a interação, a partir do espaço digital, potencializando-a por meio das ferramentas de comunicação no ciberespaço e concebendo-a como um coletivo inteligente. Para o autor, a virtualização dos conhecimentos científicos tornou-se irreversível, o que amplia a possibilidade de expansão da educação a distância apoiada nas tecnologias digitais de comunicação. Ainda, segundo Lévy, torna-se determinante a capacidade de pensar junto como sendo um novo saber necessário aos mediadores nessa modalidade de ensino.

Novas funções foram instituídas e distintos interlocutores passaram a atuar para viabilizar os processos de ensino e de aprendizagem a distância por meio dos ambientes digitais. Dentre esses atores, destaca-se o tutor. A tutoria é um elemento importante nos processos de ensinar e de aprender a distância; faz-se necessária para efetivar a mediação pedagógica nos cursos de EaD com suporte tecnológico digital. O tutor de um curso a distância atua em uma relação direta com professores formadores, alunos e conteúdos.

Entretanto, a tutoria desenvolvida por meio da Internet e apoiada por ferramentas tecnológicas (Ambiente Virtual de Aprendizagem - AVA) é uma função relativamente nova no cenário educacional, que passou a sofrer exigências pedagógicas para lidar com inúmeros desafios movidos pela escolarização em massa nessa modalidade de ensino (TARDIF, 2012). Nesse sentido, este estudo procura compreender que aspectos dessa mediação pedagógica desenvolvida pelos tutores são potencialmente capazes de significar as aprendizagens dos alunos, mudando o enfoque de um ensino 
de docência tradicional para modelos pedagógicos de ensino e de aprendizagem com ênfase na construção do conhecimento.

Ao analisar as bases pedagógicas do conhecimento analisadas por Shulman e Tardif pesquisou-se sobre os saberes necessários ao tutor a distância para mediar pedagogicamente as aprendizagens dos alunos na educação profissional a distância.

Shulman (2010) e Tardif (2012) apontam em seus estudos que o conhecimento amplo da matéria que se deseja ensinar tem íntima relação com o trabalho pedagógico. O conhecimento pedagógico do conteúdo foi o conceito utilizado para sustentar os argumentos ao problematizar o processo de mediação pedagógica realizado na educação profissional a distância do programa PROFUNCIONÁRIO.

\section{O DSC COMO ESTRATÉGIA METODOLÓGICA}

A pesquisa teve por sua natureza uma abordagem qualitativa, na qual não há separação entre o observado e a percepção de quem observa, pois não se assume uma definição prévia para a percepção do que será observado, ficando-se atento ao que se mostra no processo de investigação (BICUDO, 2011). Na pesquisa qualitativa é dada a oportunidade para que os entrevistados manifestem livremente suas opiniões sobre o tema pesquisado, onde podemos utilizar como método de coleta de dados, o questionário, entrevistas ou outros meios que intencionalmente possam produzir depoimentos.

A modalidade de pesquisa desenvolvida neste estudo classifica-se como um estudo de campo, pois foi realizada junto ao objeto de estudo. Nesta pesquisa buscou-se conhecer como o tutor a distância se apropria dos conhecimentos específicos nos cursos técnicos do programa PROFUNCIONÁRIO para mediá-los pedagogicamente com seus alunos. Para tanto, observou-se o trabalho destes tutores junto aos professores formadores e, por meio de entrevistas, elaboradas com questões abertas e norteadoras, buscou-se conhecer de que forma esse tutor se apropria dos conteúdos abordados nos diversos componentes curriculares de conhecimento geral e específico, para mediar pedagogicamente estes conhecimentos com seus os alunos.

Como procedimento metodológico, utilizou-se a técnica do Discurso do Sujeito Coletivo (DSC), de Lefèvre e Lefèvre, uma estratégia de abordagem qualitativa para analisar as recorrências encontradas nos discursos dos tutores a distância. Por meio desta metodologia buscou-se preservar as opiniões dos sujeitos investigados, evitando-se, por meio de questões fechadas, que geralmente são utilizadas em pesquisas quantitativas, decompor o tema em uma série de questões com alternativas de resposta para verificar quanto ou em que proporção um determinado atributo estaria presente.

Em termos metodológicos, a técnica do DSC visa "reconstruir, com pedaços de discursos individuais, como em um quebra-cabeça, tantos discursos-síntese quantos se julgue necessários para expressar uma dada 'figura', ou seja, um dado pensar ou representação social sobre um fenômeno" (LEFÈVRE; LEFÈVRE, 2005, p. 19).

A técnica do DSC busca preservar os pensamentos individuais de uma coletividade durante o processo de investigação, análise e apresentação dos resultados, tendo por objetivo compor um ou vários discursos-síntese na primeira pessoa do singular para "sugerir uma pessoa coletiva falando como se fosse um sujeito individual de discurso" (LEFÈVRE; LEFÈVRE, 2005, p. 32). Por meio dessa técnica, o 
pesquisador elabora o discurso-síntese com os fragmentos dos discursos individuais reunidos por similaridade de sentidos, simbolizando, de modo mais preciso, um hipotético sujeito para o qual se concede um caráter ontológico.

Os discursos coletivos são construídos por meio de expressões-chave (ECH), o que significa escolher os segmentos de texto que dão significado ao discurso, deixando de fora os trechos de conteúdo irrelevante. O Quadro 1 é um fragmento de algumas das conversações tabuladas, realizadas com os tutores a distância ao longo da pesquisa. As conversas foram transcritas na íntegra, sem correção ortográfica ou gramatical, nas células da coluna Expressões-chave da tabela denominada "Instrumento de Análise dos Discursos" (IAD1), nas quais, destaca-se, pelo recurso gráfico de cores, as ideias centrais (IC) e as ancoragens (AC).

Para descrever as ideias centrais, buscou-se analisar sinteticamente o sentido que cada argumento expressava no discurso com o mínimo possível de interpretação. Quando as expressões-chave apresentavam pressupostos ou manifestação linguística de uma teoria no depoimento, definiam-se as ancoragens. O próximo passo foi classificar as colunas da tabela, reunindo as IC e AC de sentido semelhante.

Os DSC foram construídos pelo agrupamento das ECH de diferentes depoimentos, os quais apresentavam as IC de sentido semelhante, como se fossem um só sujeito que representasse a voz da coletividade na primeira pessoa do singular.

Quadro 1: Instrumento de Análise dos Discursos - IAD1

1) Como você ajuda o aluno a aprender? A construir seu próprio conhecimento?

\begin{tabular}{|l|l|l|}
\hline \multicolumn{1}{|c|}{ Expressões-Chave } & Ideias Centrais & Ancoragem \\
\hline $\begin{array}{l}\text { (T1) instigando o aluno a realizar as atividades, assim terão a } \\
\text { interpretação do conteúdo a ser fixado, já que as atividades são } \\
\text { pensadas para que isto ocorra, e as dúvidas que surgirem ajudar o } \\
\text { aluno esclarecendo através de mensagens e feedbacks das } \\
\text { correções das atividades. }\end{array}$ & $\begin{array}{l}\text { Instigando } \\
\text { através das } \\
\text { atividades }\end{array}$ & \\
\hline $\begin{array}{l}\text { (T2) penso que minhas ações enquanto tutora devem ser de } \\
\text { incentivo ao aluno, reforçar diariamente a capacidade que cada um } \\
\text { têm de aprender a buscar conhecimento e suprir suas dúvidas. }\end{array}$ & $\begin{array}{l}\text { Por meio de } \\
\text { incentivo }\end{array}$ & \\
\hline $\begin{array}{l}\text { (T3) sendo uma mediadora, uma ponte entre o conhecimento e a } \\
\text { pesquisa. Incentivando-o sempre na construção de seu } \\
\text { conhecimento, instigando a curiosidade. }\end{array}$ & $\begin{array}{l}\text { Mediação } \\
\text { pedagógica }\end{array}$ & $\begin{array}{l}\text { Mediação } \\
\text { Pedagógica }\end{array}$ \\
\hline $\begin{array}{l}\text { (T4) eu como tutora procuro auxiliar o aluno sendo a mediadora da } \\
\text { aprendizagem. Cabe a nós tutores motivar, orientar e acompanhar } \\
\text { os alunos em suas atividades, proporcionando a eles uma } \\
\text { aprendizagem significativa, respeitando sempre as suas } \\
\text { individualidades. Acredito que o acompanhamento deve ser } \\
\text { contínuo, apresentando sempre um feedback ao aluno para que ele } \\
\text { continue motivado, por isso dou todo suporte necessário para que } \\
\text { ele se sinta autor na construção do conhecimento. }\end{array}$ & $\begin{array}{l}\text { Autor da } \\
\text { aprendizagem }\end{array}$ & \\
\hline $\begin{array}{l}\text { (T5) identificar as dificuldades e trabalhar no desenvolvimento da } \\
\text { mesma. Motivação. Ensinar o aluno a apresentar as suas } \\
\text { descobertas, pois isso estimula a todos. Me colocar como um } \\
\text { verdadeiro guia em cada jornada lançada. Isso não significa dar as } \\
\text { respostas prontas e sim mostrar os vários caminhos para encontrar } \\
\text { a resolução de um problema. }\end{array}$ & \\
\hline
\end{tabular}


(T6) sendo uma mediadora entre o professor formado e o aluno, incentivo o aluno a ir além do foi solicitado sempre dizendo "você pode escrever mais".

(T7) eu ajudo os alunos incentivando os mesmos a irem além do conteúdo que está disponível no AVA. Sugiro sempre que procurem novos textos relativos aos conteúdos que são abordados no curso para que dessa forma tenham mais conhecimento e consigam ter mais facilidade na realização das atividades propostas.

Fonte: Elaborado pelo Autor (2016)

O Quadro 2 reúne as expressões-chave de sentido semelhante em uma nova tabela (IAD2), na qual gerou-se o discurso coletivo. Para proporcionar coesão no texto do discurso coletivo, usou-se, segundo a técnica, conetivos para sequenciar as expressões-chave.

Quadro 2: Instrumento de Análise dos Discursos - IAD2

\begin{tabular}{|c|c|}
\hline Expressões-chave & Discurso Coletivo \\
\hline $\begin{array}{l}\text { Instigando o aluno a realizar as atividades, } \\
\text { assim terão a interpretação do conteúdo a } \\
\text { ser fixado, já que as atividades são } \\
\text { pensadas para que isto ocorra, e as } \\
\text { dúvidas que surgirem ajudar o aluno } \\
\text { esclarecendo através de mensagens e } \\
\text { feedbacks das correções das atividades. } \\
\text { Penso que minhas ações enquanto tutora } \\
\text { devem ser de incentivo ao aluno, reforçar } \\
\text { diariamente a capacidade que cada um } \\
\text { têm de aprender a buscar conhecimento e } \\
\text { suprir suas dúvidas. } \\
\text { Incentivando-o sempre na construção de } \\
\text { seu conhecimento, instigando a } \\
\text { curiosidade. } \\
\text { Eu ajudo os alunos incentivando os } \\
\text { mesmos a irem além do conteúdo que } \\
\text { está disponível no AVA. Sugiro sempre que } \\
\text { procurem novos textos relativos aos } \\
\text { conteúdos que são abordados no curso } \\
\text { para que dessa forma tenham mais } \\
\text { conhecimento e consigam ter mais } \\
\text { facilidade na realização das atividades } \\
\text { propostas. }\end{array}$ & $\begin{array}{l}\text { Penso que minhas ações enquanto tutora devem } \\
\text { ser de incentivo ao aluno para reforçar } \\
\text { diariamente a capacidade que cada um têm de } \\
\text { aprender a buscar conhecimento e suprir suas } \\
\text { dúvidas. Eu ajudo os alunos incentivando os } \\
\text { mesmos a irem além do conteúdo que está } \\
\text { disponível no AVA, instigando a curiosidade do } \\
\text { aluno a realizar as atividades. Assim, terão a } \\
\text { interpretação do conteúdo a ser fixado. Dessa } \\
\text { maneira, sugiro sempre que procurem novos } \\
\text { textos relativos aos conteúdos que são abordados } \\
\text { no curso para que assim, tenham mais } \\
\text { conhecimento e consigam ter mais facilidade na } \\
\text { realização das atividades propostas. Do mesmo } \\
\text { modo, para as dúvidas que surgirem, ajudo o } \\
\text { aluno esclarecendo, através de mensagens e } \\
\text { feedbacks, das correções das atividades, } \\
\text { incentivando-os sempre na construção de seu } \\
\text { conhecimento. }\end{array}$ \\
\hline
\end{tabular}

Fonte: Elaborado pelo Autor (2016)

Os quadros apresentados demonstram um exemplo da técnica que se utilizou para analisar os depoimentos obtidos pelos tutores a distância do programa PROFUNCIONÁRIO por meio de um questionário que teve como questões:

- Como você ajuda o aluno a aprender? A construir seu próprio conhecimento?

- Como você faz para mediar conhecimentos específicos junto ao aluno através da tutoria, quando os conteúdos não são de seu domínio conceitual? 
- Nos cursos do programa PROFUNCIONÁRIO, percebe-se em geral a falta de interação entre o tutor a distância e o tutor presencial. Qual a sua opinião a respeito?

- Visando fortalecer o processo de ensino e de aprendizagem no programa PROFUNCIONÁRIO, o que você julga importante ressaltar?

\section{APRESENTAÇÃO E DISCUSSÃO DOS DADOS}

O objetivo do estudo foi conhecer o trabalho desenvolvido para problematizar as próprias ações e, compreendendo-as, encontrar alternativas plausíveis e necessárias capazes de aprimorar tal processo.

Por meio dos temas recorrentes observados nos depoimentos contidos nas respostas dos questionários, foram gerados dois discursos coletivos: "Domínio conceitual e pedagógico dos conteúdos"; "Normatizar como proposta para efetivar a Interação.

O primeiro discurso coletivo (DSC1) foi construído tendo como ideia central a mediação pedagógica de conhecimentos específicos junto ao aluno, quando os conteúdos não são do domínio conceitual do tutor.

DSC1. Domínio conceitual e pedagógico dos conteúdos

Para poder mediar a aprendizagem de conteúdos que não são de minha formação, procuro realizar um
trabalho próximo ao professor formador, fazendo um trabalho em conjunto, pois acho estranho corrigir
trabalhos que não fui eu que elaborei nem preparei os conteúdos e são muitas respostas pessoais, difícil de
avaliar e atribuir notas. Mas claro que li o Projeto Pedagógico do curso e as funções de cada um, sei que é
função do tutor a distância. Assim, assisto os vídeos e pesquiso em outros sites quando não domino o
conteúdo, para que dessa forma seja possível eu ajudar e também consiga sanar as dúvidas dos alunos. A
leitura dos conteúdos é o primeiro passo para estarmos atualizados e o diálogo com o professor formador
também é de suma importância para estarmos bem preparados para mediarmos conhecimentos específicos
com nossos educandos. Em outras palavras, através das visualizações das vídeo-aulas, leitura do material
disponibilizado e discussão das atividades com o professor formador e com outros colegas, tutores
presenciais, suporte pedagógico e o suporte técnico, nós, tutores nos apropriamos desses conhecimentos
podendo dessa forma auxiliar e avaliar os alunos.

A falta de domínio conceitual e pedagógico dos conteúdos nos componentes curriculares pode causar desconforto e insegurança ao tutor a distância para mediar o aluno em seus estudos, gerando pouca interatividade entre eles e configurando um trabalho de mediação essencialmente burocrático, sem atuação efetiva no processo de mediação pedagógica dos conhecimentos curriculares.

O processo de mediação pedagógica na educação profissional a distância se potencializa na manutenção de uma rede de conversação criativa e problematizadora entre seus protagonistas, tornando-se essencial que as atividades curriculares sejam didaticamente discutidas nesse coletivo antes de serem trabalhadas junto aos alunos. Segundo Moraes (2003, p. 2013), durante o processo de mediação pedagógica,

[...] a postura do professor e a didática utilizada são muito importantes, pois podem tanto incentivar o diálogo, quanto encerrar o fluxo mediante posicionamentos inadequados, oferecimento de respostas prontas, ou mesmo tecendo algum comentário que diminua o interesse e a participação do aluno, provocando assim o rompimento do diálogo. 
Redes de conversação recursivas entre o professor formador e os tutores como estratégia de formação favorecem o trabalho coletivo e colaborativo. É nessa relação que se (re)organizam os conhecimentos abordados nos componentes curriculares a partir das reflexões geradas nesse espaço operacional de convivência. Nesse processo, cada um (re)interpreta, (re)constrói e (re)contextualiza seu conhecimento, influenciado pelos saberes teóricos e práticos produzidos na relação com o outro.

Percebe-se por meio do discurso coletivo que nesse modelo de ensino, torna-se imperativo que o professor formador trabalhe seu componente curricular com os tutores, pois é nessa interação que o mesmo pode se apropriar conceitual e pedagogicamente dos conhecimentos específicos para mediálos com os alunos.

Assim, tanto o tutor a distância quanto o professor formador se transformam na convivência, pois são levados a refletir sobre suas ações, seus papéis, suas dificuldades, seus desafios, a pensar sobre o que sabem e o que não sabem, e o que fazer para sanar o que Ihes falta. Assim, na recursividade do conversar, o tutor a distância apropria-se da condição de sujeito do próprio aprendizado e compreende pedagogicamente os conceitos técnicos e específicos para (re)significá-los no processo de mediação com os alunos.

No modelo de EaD desenvolvido no PROFUNCIONÁRIO, existe uma particularidade que são os encontros pedagógicos do tutor a distância com o professor formador exercidos semanalmente de forma presencial. Xavier, Ferreira e Ávila (2013) destacam que a configuração de um espaço físico que permita a convivência entre os sujeitos constitui-se em condição essencial para a existência de processos de inteligência coletiva. Para os autores, esses ambientes devem favorecer "a expressão de pensamentos, o desenvolvimento da percepção do outro, da escuta sensível e da autonomia", tornando-se importante o "reconhecimento de todos a respeito de seu próprio valor e do valor de cada um dos membros da comunidade, os quais, em suas diversidades, estarão contribuindo para a geração de processos de inteligência coletiva" (XAVIER; FERREIRA; ÁVILA, 2013, p. 4). Para Lévy (1998, p. 31), num coletivo inteligente, seus membros assumem como objetivo "a negociação permanente da ordem estabelecida, de sua linguagem, do papel de cada um, o discernimento e a definição de seus objetos, a reinterpretação de sua memória".

Um trabalho conjunto também possibilita ao tutor um conhecimento curricular lateral, ou seja, aquele conhecimento adquirido ao atuar em diferentes disciplinas do curso (SHULMAN, 2010). A familiaridade do tutor com temas e questões trabalhadas em outras disciplinas do curso permite uma relação dos conteúdos com o professor formador num contexto mais amplo, desde que o processo de interação pedagógica se efetive entre eles.

No segundo discurso coletivo (DSC2) emergiu o aspecto da falta de interação entre os tutores presenciais e os tutores a distância e o seu impacto sobre o processo de mediação com os alunos.

DSC2. Normatizar como proposta para efetivar a Interação

Acho que os tutores presenciais deveriam estar orientados e cobrados a manter contato com o tutor a distância e com os alunos. Por exemplo, verificar se o aluno compareceu ao polo no dia presencial, verificando se a atividade que já passou uma semana aberta não foi realizada, fazer um corpo a corpo, já que está ali com aluno, talvez este aluno esteja precisando de uma explicação. Assim, ficará mais fácil realizar a atividade e/ou pedir que ele entre em contato com o tutor a distância. Além disso, enviar mensagem, deixando o tutor a distância ciente de que ele está percebendo das dificuldades do aluno. Em síntese, criar um vínculo mais próximo do aluno. Eu como tutor à distância procuro sempre os tutores presenciais, procurando sempre manter uma relação de interação para ajudar os alunos. Entretanto, 
realmente eu não consigo interagir da forma como eu acho necessária. Poucas vezes obtive respostas ou em outras vezes elas vinham, mas demoravam tanto que eu até já tinha solucionado o problema. Não sei se isto se deve à falta de tempo dos mesmos, ou se realmente estes não julgam ser necessária tais interações. A aproximação de tutores a distância e tutores presenciais fortalece as ações pedagógicas, oportunizando um trabalho de equipe, com consequentemente maior qualidade nos cursos oferecidos pelo PROFUNCIONARIO. Seria de extrema importância ao longo dos 2 anos do curso que houvessem encontros entre ambos, visita aos polos, ter um olhar olho a olho, trocar experiências, o que, na minha opinião, favoreceria essa aproximação e acrescentaria ao nosso trabalho, principalmente no início do curso. Também acredito que deveria ter um empenho maior por parte dos coordenadores de polo e tutores presenciais para não haver evasão, eles estão pertos dos alunos, os conhecem pessoalmente, poderiam resgatar com mais facilidade, olho no olho, como se diz. Tutores a distância, tutores presenciais e coordenadores de polo poderiam se reunir e traçar estratégias que seriam utilizadas durante o curso, e dessa forma, facilitaria o processo da aprendizagem.

A sugestão de uma normatização, apontada nos discursos coletivos emergiu como um desejo dos tutores a distância de que sejam formalizadas políticas para institucionalizar uma rede de conversação recursiva com os tutores presenciais.

Por meio do discurso, percebe-se a necessidade de que o trabalho na confluência de uma rede de conversação recursiva entre professores formadores e tutores a distância se estenda aos tutores presenciais, na qual os conhecimentos específicos possam ser discutidos e customizados coletivamente de acordo com os recursos e ferramentas disponíveis no AVA. Em um trabalho conjunto, ambos podem complementar seus conhecimentos teóricos e práticos imbricados com as tecnologias, contribuindo, cada um, com os saberes específicos de sua área de conhecimento.

Maturana (2002) ressalta que ainda vivemos em uma cultura que instrumentaliza a educação, fazendo com que usemos a relação educativa com propósitos que estão além da relação consensual. Assim, para que haja transformação na convivência, são necessárias relações de aceitação legítimas e espontâneas, sem submissão e sem competição entre seus membros. Nesse sentido, acredita-se que as redes de conversação configuradas na reciprocidade de aceitação e respeito mútuo sejam um espaço de transformação e apropriação de conhecimentos, capazes de sustentar o processo de mediação pedagógica a distância nesse novo meio de comunicação digital, porque possibilitam gerar situações experienciais que potencializam situações de colaboração.

O discurso coletivo ainda reafirma a ideia de Peters (2012), ressaltando a importância dos encontros presenciais entre professores formadores, tutores presenciais e tutores a distância. Peters (2012, p. 70) lembra que a forma natural de interação pedagógica decorre da oralidade, qual seja, "falar e ouvir em situações face a face". Para o autor "a mudança de ensino e aprendizagem oral para um sistema mediado tecnicamente representa um rompimento sério com a tradição acadêmica" (PETERS, 2012, p. 71). Ressalta ainda a inquietude e a insegurança que podem ocorrer nos professores por conta da emergência da mídia de informação e comunicação digital, pois, nesse modelo de ensino não há uma interação direta, "falar e ouvir são substituídos por escrever e ler, outro padrão cultural que, no entanto, é relativamente novo e, certamente, comparativamente difícil" (PETERS, 2012, p. 71).

\section{CONSIDERAÇÕES FINAIS}

A educação profissional a distância, customizada virtualmente pelos meios de comunicação digital, configura uma nova maneira de ensinar e de aprender conhecimentos técnicos e profissionalizantes para o mundo do trabalho. As tecnologias de informação e de comunicação digital flexibilizaram o 
processo de mediação pedagógica no tempo e no espaço, permitindo a construção de saberes por meio de interações síncronas e assíncronas em rede.

O estudo problematizou o processo de mediação pedagógica na educação profissional a distância do programa PROFUNCIONÁRIO da Rede e-Tec no IFSul como uma atividade que, entende-se pelo estudo, ser desempenhada primordialmente no coletivo. Neste sentido, percebe-se a necessidade de se intensificar um trabalho conjunto entre os professores formadores e os tutores presenciais e a distância, para que a falta de conhecimentos a respeito dos conteúdos específicos abordados seja superada na convivência presencial/virtual e as dúvidas esclarecidas durante as interações. Assim, o processo de mediação pedagógica dos tutores com os alunos poderá ser realizado com referencial teórico e prático.

Na educação profissional a distância do Programa PROFUNCIONÁRIO há uma rotatividade expressiva dos professores formadores por conta do número de disciplinas que compõe os currículos de cada curso técnico. Numa perspectiva singular, esses professores têm autonomia para definir quais as estratégias metodológicas irão utilizar no decorrer de seus componentes curriculares, mas ao observar-se que nesse modelo de ensino quem assume o processo de mediação pedagógica com o aluno são os tutores, aponta-se que somente num trabalho coletivo e colaborativo é que tal processo pode tornar-se efetivamente significativo.

No modelo de ensino profissional a distância do programa PROFUNCIONÁRIO, pensar no coletivo torna-se essencial para que os tutores possam se apropriar dos conhecimentos específicos e planejar pedagogicamente como mediá-los em parceria com os professores formadores. Com o domínio do conteúdo, os tutores podem encontrar estratégias pedagógicas para sistematizar os conceitos curriculares em sua prática. Sem esse domínio, as discussões tornam-se vagas ou superficiais, desmotivando tanto os alunos quanto os próprios mediadores nos processos de ensinar e de aprender a distância.

Objetivando minimizar as distâncias e ampliar a rede de conversação recursiva, em julho de 2015, foi customizado um "fórum de tutores" no ambiente virtual de cada componente curricular. Entretanto, a participação no fórum ainda é muito tímida, o que revelou a ausência de uma relação social coletiva e colaborativa, revelando a carência de trabalhos realizados em comum acordo entre os professores formadores e os tutores presenciais e a distância durante o desenvolvimento das disciplinas.

Conforme Lévy (1998), a inteligência coletiva pressupõe reinventar um laço social em torno do aprendizado recíproco, pois é na relação com o outro que fazemos viver o saber. Com a pesquisa ficou evidente a necessidade e a urgência de criar e fortalecer espaços para que possamos saber, conforme indaga LÉVY (1998, p. 27):

[...] quem é o outro? É alguém que sabe. $E$ que sabe as coisas que eu não sei. $O$ outro não é mais um ser assustador, ameaçador: como eu, ele ignora bastante e domina alguns conhecimentos. Mas como nossas zonas de inexperiência não se justapõem ele representa uma fonte possível de enriquecimento de meus próprios saberes. Ele pode aumentar meu potencial de ser, e tanto mais quanto mais diferir de mim. Poderei associar minhas competências às suas, de tal modo que atuemos melhor juntos do que separados. 
Apenas estar em uma rede de conversação não configura um coletivo inteligente. É preciso que políticas de intervenção pedagógica sejam efetivas para que as redes de conversação aproximem o mundo acadêmico presencial do mundo acadêmico virtual, pois são sujeitos vivendo juntos em espaços colaborativos, problematizando temas algumas vezes divergentes, que emergem das experiências vividas de cada um. O saber é, assim, produzido por meio das interações com o outro, no coletivo, transformando a cultura do individualismo e, do professor especialista, possibilitando que se perceba que, nessa era digital, a informação está disponível e o que está em jogo é ensinar e aprender no coletivo, em situação de desterritorialização, em redes de conversação que constituem os coletivos inteligentes.

Outra alternativa para a falta de conhecimento conceitual e pedagógico dos conteúdos curriculares específicos, além do fórum de tutores, poderia ser implementada com a utilização de espaços de áudio (Podcast), com temas escolhidos e discutidos em redes de conversação de maneira espontânea entre os professores formadores e os tutores a distância durante os encontros pedagógicos semanais, favorecendo a formação de processos de inteligência coletiva. As conversas seriam gravadas, editadas e disponibilizadas no AVA, e os temas geradores das conversas poderiam ser as próprias dúvidas dos alunos postadas nos fóruns de discussão do componente curricular.

Assim, como encaminhamentos futuros, visando potencializar o processo de mediação pedagógica na educação profissional a distância do programa PROFUNCIONÁRIO, no caminho para uma cultura da inteligência coletiva, apresentam-se algumas observações que se julga importante ressaltar:

- retomar e intensificar o trabalho interativo do tutor a distância com o tutor presencial no fórum de tutores, de forma assíncrona, bem como no uso de ferramentas de comunicação síncrona (chats ou serviços de mensagem instantânea), possibilitando que suas conversações virtuais ocorram em tempo real;

- a realização prévia das atividades propostas nas disciplinas pelos tutores a distância, para a busca de possíveis problemas de interpretação ou execução;

- o desenvolvimento de arquivos de áudio do tipo podcast e webconferências, a partir de um trabalho coletivo e colaborativo entre os professores formadores e os tutores a distância.

Uma rede de conversação recursiva constituída gera uma possibilidade de trabalho coletivo e colaborativo entre o professor formador e o tutor. Nesse ambiente de convívio, potencializado pelos recursos do meio digital (por exemplo, fórum de discussão, chat, mensagem instantânea, webcoconferência, podcast), ambos podem relacionar seus saberes e (re)definir os rumos pedagógicos, primando pela difusão de conhecimentos e aprendizagens com o desenvolvimento dos pensamentos complexo e reflexivo nos cursos técnicos profissionalizantes.

Segundo Maturana e Varela (2001), as bases biológicas do aprendizado se encontram em nossa história de vida, em que o conhecer não se separa do viver. Assim, as aprendizagens ocorrem pela/na convivência por meio das interações recorrentes que acontecem nos encontros entre os sujeitos que dela participam por meio do conversar. Desse ponto de vista, compreendemos a mediação pedagógica na educação a distância como uma função a ser reconfigurada, de tal modo que os professores formadores, os tutores presenciais e a distância possam juntos se transformar na convivência de maneira mútua, no fluir recorrente de seus encontros presenciais/virtuais por meio de suas conversações. 
Ao final, apoiado por uma pergunta iluminadora de Maturana (2001), convida-se os possíveis leitores a refletir sobre que cultura queremos conservar no viver e no conviver dos professores formadores com os tutores presenciais e a distância em redes de conversação no programa PROFUNCIONÁRIO da Rede e-Tec do IFSul?

\section{REFERÊNCIAS}

BICUDO, M. A. V. Pesquisa qualitativa segundo a visão fenomenológica. São Paulo: Cortez, 2011.

LEFÈVRE, F.; LEFÈVRE, A. M. O discurso do sujeito coletivo: um novo enfoque em pesquisa qualitativa (desdobramentos). Caxias do Sul: Educs, 2005.

LÉVY, P. A Inteligência coletiva: por uma antropologia do ciberespaço. São Paulo: Loyola, 1998.

Cibercultura. São Paulo: Ed. 34, 1999.

MATURANA, H. A ontologia da realidade. Belo Horizonte: Ed. UFMG, 2002.

MATURANA, H.; VARELA, F. A árvore do conhecimento: as bases biológicas da compreensão humana. São Paulo: Palas Athenas, 2001.

MORAES, M. C. Educar na biologia do amor e da solidariedade. Petrópolis: Vozes, 2003.

MORAN, J. M. A educação que desejamos: Novos desafios e como chegar lá. Campinas, SP: Papirus, 2007.

PETERS O. A educação a distância em transição: tendências e desafios. São Leopoldo: Unisinos, 2012.

PROFUNCIONÁRIO. Instituto Federal de Educação, Ciência e Tecnologia Sul-rio-grandense (IFSul). Projeto Pedagógico do Curso Técnico em Multimeios Didáticos. Documento Básico. Pelotas, 2012. Disponível em:< http://pt.calameo.com/read/00192564854112cbf60e9>. Acesso em: 29 Jun. 2016.

SHULMAN, L. Aprendizagem Baseada em Problemas (ABP) requer que os estudantes assumam os riscos de expor suas opiniões e ideias. Divulgación y Cultura Científica Iberoamericana. 2010. Disponível em: <http://www.oei.es/divulgacioncientifica/entrevistas_071.htm>. Acesso em: 06 Mai. 2016.

TARDIF, M. Saberes docentes e formação profissional. Petrópolis, RJ: Vozes, 2012.

XAVIER, R.; FERREIRA, M.; Ávila, C. Pensamos juntos, logo existimos: ensaios para geração de processos de Inteligência Coletiva em capacitação para equipe EaD. Oitava Conferência LatinoAmericana de Objetos de Aprendizagem e Tecnologias - LACLO. Vol 4, num. 1, 2013. 